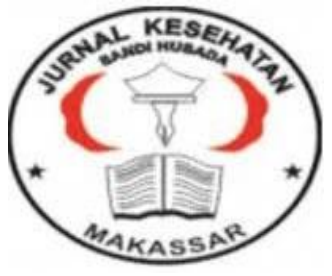

Jurnal Ilmiah Kesehatan Sandi Husada

hhttps://akper-sandikarsa.e-journal.id/IIKSH

Volume 9, Nomor 2, Desember 2020, pp 748-752

p-ISSN: 2354-6093 dan e-ISSN: 2654-4563

DOI: $10.35816 /$ jiskh.v10i2.398

\title{
Kualitas Pelayanan Kesehatan di Puskesmas Padongko
}

Quality of Health Services at Public Health Center Padongko

\author{
A.Pananrangi $\mathrm{M}^{1}$, Andi Tenri Nippi ${ }^{2}$, Rahmat Panyyiwi ${ }^{3}$, Suprapto Suprapto ${ }^{4}$ \\ 12 Sekolah Tinggi Ilmu Administrasi (STIA) Al Gazali Barru \\ ${ }^{3}$ Akademi Keperawatan Yapenas 21 Maros \\ ${ }^{4}$ Program Studi Keperawatan Politeknik Sandi Karsa
}

\section{Artikel info}

Artikel history:

Received; Juli 2020

Revised: Agustus 2020

Accepted; Agustus 2020

\begin{abstract}
Abstrak
Abstrak. Latar belakang; semakin meningkatnya kesadaran masyarakat akan haknya dalam memeperoleh pelayanan termasuk pelayanan kesehatan merupakan salah satu indikator positif meningkatnya kesadaran akan pentingnya kesehatan. Penelitian ini bertujuan untuk mengetahui kualitas pelayanan kesehatan di Puskesmas Padongko Kecamatan Barru Kabupaten Barru. Metode: penelitian ini tipe penelitian yang digunakan adalah dekriftif kualitatif. Data yang digunakan adalah data primer dan data sekunder. Untuk data primer sebagai informan adalah: pegawai Puskesmas Padongko, pasien dan tokoh masyarakat. Sementara data skunder dilakukan melalui penelusuran kepustakaan, jurnal dan karya ilmiah lainnya. Teknik pengumpulan data adalah: wawancara, observasi dan dokumentasi. Kemudian teknik analisis data yaitu; reduksi data, penyajian data, dan penarikan kesimpulan. Hasil penelitian menunjukkan bahwa meskipun masih kekurangan sarna dan prasarana, namun secara umum dapat disimpulkan bahwa Puskesmas Padongko sudah menunjukkan kualitas pelayanan kesehatan yang cukup baik. Kesimpulan: meskipun masih kekurangan sarana dan prasarana, namun secara umum dapat disimpulkan bahwa Puskesmas Padongko sudah menunjukkan kualitas pelayanan kesehatan yang cukup baik.
\end{abstract}

Abstract. Background; Increasing public awareness of their rights to obtain services, including health services, is a positive indicator of increasing awareness of the importance of health. This study aims to determine the quality of health services at Puskesmas Padongko, Barru District, Barru Regency. Methods: This research type used is descriptive qualitative. The data used are primary data and secondary data. Primary data as informants are: Puskesmas Padongko staff, patients 
and community leaders. Meanwhile, secondary data is carried out through literature searches, journals and other scientific works. Data collection techniques are: interviews, observation and documentation. Then the data analysis techniques, namely; data reduction, data presentation, and drawing conclusions. The results showed that although there was still a lack of facilities and facilities, in general it could be concluded that Puskesmas Padongko had shown a fairly good quality of health services. Conclusion: although there is still a lack of facilities and infrastructure, in general it can be concluded that Puskesmas Padongko has shown a fairly good quality of health services.

\author{
Keywords: \\ Quality of Health \\ Services; \\ Public Health Center;
}

Coresponden author:

Email: pananrangia@mail.com

artikel dengan akses terbuka dibawah lisensi CC BY 4.0

\section{Pendahuluan}

Setiap orang mempunyai hak dalam memperoleh pelayanan kesehatan yang aman, bermutu, dan terjangkau. Dalam Undang-Undang Republik Indonesia Nomor 36 Tahun 2009 Tentang Kesehatan dijelaskan bahwa kesehatan adalah keadaan sehat, baik secara fisik, mental, spritual maupun sosial yang memungkinkan setiap orang untuk hidup produktif secara sosial dan ekonomis. Implementasi kebijakan diskresi birokrasi dalam pemerintahan daerah sebagai salah satu upaya efektivitas pelayanan public diterbitkannya dalam keadaan mendesak yaitu suatu keadaan yang muncul secara tibatiba menyangkut kepentingan umum yang harus diselesaikan dengan cepat, dimana untuk menyelesaikan persoalan tersebut, peraturan perundang undangan belum mengaturnya atau hanya mengatur secara umum dan keadaan tersebut tidak boleh tercipta karena kesalahan tindakan oleh Badan atau Pejabat Administrasi Pemerintahan yang melakukan diskresi. Pemerintah mengeluarkan kebijakan diskresi yakniJaminan Kesehatan(Suprapto, 2019). Terjadinya fenomena beberapa kebijakan yang dibatalkan atau direvisi oleh Pemerintah merupakan indikasi masih adanya tumpang tindih kebijakan dan rendahnya kemampuan berinovasi dan kemauan berinovasi pejabat publik. Untuk itu diperlukan inovasi kebijakan yang memberikan penguatan dalam menyelesaikan permasalahan ditengah masyarakat (A.Pananrangi M, 2019).

Upaya kesehatan yang diselenggarakan di Puskesmas terdiri dari Upaya Kesehatan Wajib dan Upaya Kesehatan Pengembangan. Upaya Kesehatan Wajib memberikan daya ungkit yang sangat besar terhadap keberhasilan pembangunan kesehatan masyarakat melalui peningkatan Indeks Pembangunan Manusia (IPM), serta merupakan kesepakatan global maupun nasional. Upaya Kesehatan Wajib terdiri dari promosi kesehatan ibu anak (KIA), keluarga berencana (KB), kesehatan lingkungan dan lain-lain. Sedangkan, Upaya Kesehatan Pengembangan adalah upaya kesehatan yang telah ditetapkan berdasarkan permasalahan kesehatan masyarakat setempat dan disesuaikan dengan kemampuan puskesmas antara lain upaya kesehatan gigi dan mulut, upaya kesehatan jiwa, upaya kesehatan mata, pembinaan pengobatan tradisional, dan perawatan kesehatan masyarakat (Andrianto \& Nursikuwagus, 2017).

Hal ini terjadi karena di satu sisi tuntutan masyarakat terhadap kualitas pelayanan semakin besar sementara praktek penyelenggara pelayanan tidak mengalami perubahan 
yang berarti. Masyarakat setiap waktu menuntut pelayanan publik yang berkualitas, meskipun tuntutan tersebut sering tidak sesuai dengan harapan karena pelayanan publik yang terjadi selama ini masih berbelit-belit, lambat, mahal, dan melelahkan (Yayat, 2017).

Desa adat yang mungkin mempunyai istilah lain, kemudian disebut desa sebagai masyarakat hukum yang mempunyai batas wilayah dan kewenangan mengatur dan mengurus urusan pemerintahan, kepentingan masyarakat setempat berdasarkan kemauan, asal usulnya. hak, dan hak tradisional yang diakui dan dihormati dalam sistem pemerintahan Republik Indonesia. Dinyatakan bahwa dana desa bersumber dari APBN yang disalurkan melalui APBD (Pananrangi, 2019). Berdasarkan hasil penelitian (Suprapto, 2018) menunjukan bahwa pengetahuan masyarakat sebagian masih kurang akan tetapi dengan pengetahuan yang ada tidak mempengaruhi sikap masyarakat dalam upaya pencegahan. Perlu ditingkatkan lagi penyuluhan yang lebih intensif dalam rangka menggerakkan masyarakat dalam upaya pencegahan penyakit.

\section{Metode}

Dalam penelitian ini tipe penelitian yang digunakan adalah dekriftif kualitatif. Penelitian ini dilaksanakan di Puskesmas Padongko Kecamatan Barru Kabupaten Barru yan dilaksanakan selama 3 bulan mulai bulan januari sampai bulan Maret Tahun 2020. Data yang digunakan adalah data primer dan data sekunder. Untuk data primer sebagai informan adalah: pegawai Puskesmas Padongko, pasien dan tokoh masyarakat. Sementara data skunder dilakukan melalui penelusuran kepustakaan, buku, junal dan karya ilmiah lainnya. Teknik pengumpulan data adalah : wawancara, observasi dan dokumentasi. Kemudian teknik analisis data yang digunakan terdiri dari tiga tahap yaitu; reduksi data, penyajian data, dan penarikan kesimpulan.

\section{Hasil Dan Pembahasan}

Setelah dilakukan wawancara dengan informan sesuai dengan landasan teori yang digunakan (Pasolong, 2011), bahwa 5 (lima) dimensi kualitas pelayanan (Servqual), yaitu: Tangibles (bukti langsung); dari keterangan yang diperoleh mengenai aspek tangibles, diketahui sarana dan prasarana pendukung dalam pelayanan kesehatan masih minim sehingga belum sepenuhnya dapat memuaskan pelayanan kesehatan masyarakat. Sebagian pasien yang sebenarnya masih mampu dirawat oleh Puskesmas, namun karena sebagian sarana dan parasana belum ada akhinya harus diujuk di Rumah Sakit. Peran pemerintah daerah dalam peningkatan pelayanan kesehatan dilihat dari instrument kebijakan yang dipakai pemerintah daerah adalah instrument wajib. Penggunaan instrumen wajib ini terlihat dari besarnya peran pemerintah dalam pelayanan kesehatan tanpa ada campur tangan swasta. Faktor pendukung terdiri dari: dukungan penuh pembiayaan fasilitas medis dan biaya operasional rumah sakit, aturan yang menjadi landasan kerja pelayanan dan kunjungan pasien yang terus mengalami peningkatan dari tahun ke tahun (Podungge, 2010).

Reliability (keandalan); berdasarkan keterangan informan diketahui bahwa para petugas di Puskesmas Padongko sudah cukup memiliki cukup kemampuan untuk memberi pelayanan secara tepat dan benar. Secara tepat berarti tahu dan mengerti tugas dan tanggung jawabnya persis seperti yang diharuskan dalam ketentuan, dan cepat berarti mampu menyelesaikan tugasnya sesuai dengan waktu yang ditentukan. Hasil penelitian (Rosdiana, dkk, 2017) kualitas pelayanan kesehatan di Kota Serang mencapai 59,39\% yang mana menunjukan angka di bawah 65\%, hal tersebut dikarenakan masih terdapatnya Puskesmas yang menyediakan fasilitas fisik yang kurang memadai, masih terdapatnya petugas yang memberikan pelayanan tidak sesuai dengan yang dijanjikan, 
keterlambatan membuka loket, kurang cepat nya pelayanan yang diberikan, kurangnya sosialisasi yang diberikan, dan masih terdapatnya petugas layanan yang kurang ramah dalam memberikan pelayanan kepada masyarakat

Responsiveness (daya tanggap), keinginan para staf atau pegawai untuk membantu para pelanggan dan memberikan pelayanan dengan tanggap; dari informan diketahui bahwa petugas pelayanan meskipun melayani pasien yang banyak, dan jenis penyakit yan berbeda-beda tetapi tetap semangat dan tanpa kenal lelah melayani pasien. Ini berati petugas layanan menujukkan kenginan, semangat dan daya tanggap dalam menjalankan tugas. Menurut hasil penelitian (Fahrepi, dkk, 2019) bahwa kehandalan, jaminan, bukti langsung, empati dan daya tanggap dalam pelayanan home care berhubungan dengan kepuasan keluarga pasien. Disarankan kepada pihak pelayanan Home care di Puskesmas Batua hendaknya lebih memperomosikan lagi pelayanan Home care dan tetap mempertahankan model pelayanan asuhan keperawatan yang ada. Berdasarkan hasil penelitian (Suprapto, 2016) bahwa faktor-faktor stres kerja perawat dengan mutu pelayanan keperawatan di Ruangan Instalasi Rawat Darurat Rumah Sakit Daerah Salewangan Maros adalah faktor beban kerja dan hubungan interpersonal.

Assurance (jaminan); dari aspek assurance diketahui petugas pelayanan sudah memiliki pengetahuan dan kemampuan melaksanakan tugas sesuai Standar Operaisonal Prosedur (SOP), dan selalu menunjukkan sikap yang meyakinkan sehingga dapat dipercaya oleh pasien. Hasil penelitian (Ginting, 2014)menunjukkan pengetahuan perawat di IGD RSUP. H. Adam Malik tentang standar JCI keselamatan pasien pada kategori kurang sebesar $50,8 \%$. Ada hubungan yang signifikan antara variabel pengetahuan perawat dengan penerapan standar JCI tentang keselamatan pasien. Kemampuan perawat di IGD RSUP. H. Adam Malik tentang standar JCI keselamatan pasien pada kategori kurang sebesar 52,5\%. Ada hubungan yang signifikan antara variabel kemampuan perawat dengan penerapan standar JCI tentang keselamatan pasien. Bahwa ada hubungan antara kepuasan kerja perawat dengan prestasi kerja perawat pelaksana sedangkan tidak ada hubungan antara komitmen denga prestasi kerja perawat. Pada umumnya dan pelayanan keperawatan pada khususnya untuk tetap mempertahankan atau lebih ditingkatkan lagi kulitas pelayanannya, khususnya yang berkaitan dengan kinerja perawat sehingga dapat memuaskan pasien (Suprapto, 2018).

Emphaty (empati); dalam hal empati diketahui bahwa petugas pelayanan juga sering komunikasi secara pribadi dengan pasien, sehingga pasien terbuka menyampaikan faktor penyebab sakitnya dan terbuka menyampaikan keinginannya. Dengan komunikasi yang terbangun tersebut memudahkan dokter dan perawat untuk melakukan elayanan kesehatan yang berkualitas. Hasil penelitian (Astarani \& Pradinata, 2015) menunjukkan responden menilai perilaku empati perawat dalam komponen kognitif kurang baik sebesar 67,2 \%, komponen afektif kurang baik sebesar 75,9 \%, dan komponen komunikatif kurang sebesar 60,3 \%. Perilaku empati perawat baik dari komponen kognitif, afektif, dan komunikatif dalam melaksanakan asuhan keperawatan kurang baik. Dalam melakukan implementasi keperawatan berdasarkan dengan rencana tindakan keperawatan, Evaluasi keperawatan menunjukkan bahwa tidak semua masalah dapat teratasi mengingat kondisi pasien.Diharapkan kepada untuk perawat mampu memberikan asuhan keperawatan secara komprehensif kepada pasien(Suprapto, 2017).

\section{Simpulan Dan Saran}

Meskipun masih kekurangan sarna dan prasarana, namun secara umum dapat disimpulkan bahwa Puskesmas Padongko sudah menunjukkan kualitas pelayanan kesehatan yang cukup baik. Puskesmas Padongko untuk kelengkapan sarana dan 
prasarana agar mengajukan anggaran ke Pemerintah Daerah Kabupaten Barru agar pelayanan kesehatan masyarakat dapat ditingkatkan.

\section{Daftar Rujukan}

A.Pananrangi M. (2019). Inovasi Kebijakan Publik Dalam Perspektif Administrasi Publik. Meraja Jurnal, 2(3), 1-13.

Andrianto, P., \& Nursikuwagus, A. (2017). Sistem Informasi Pelayanan Kesehatan Berbasis Web di Puskesmas. Seminar Nasional Komputer Dan Informatika, 6.

Astarani, K., \& Pradinata, M. J. (2015). Pentingnya Perilaku Empati Perawat dalam Melaksanakan Asuhan Keperawatan. JURNAL STIKES RS Baptis Kediri, 8(1).

Fahrepi, R., Rate, S., \& Hadi, A. J. (2019). Hubungan Kualitas Pelayanan Home Care Dengan Tingkat Kepuasan Keluarga Pasien Di Wilayah Kerja Puskesmas Batua Kota Makassar. PROMOTIF: Jurnal Kesehatan Masyarakat, 9(1), 122-128.

Ginting, D. S. (2014). Hubungan Pengetahuan Dan Kemampuan Perawat Dengan Penerapan Standar Joint Commission International Tentang Keselamatan Pasien Di Instalasi Gawat Darurat RSUP. H. Adam Malik Medan.

Pananrangi, M. (2019). The Analysis Of Management And Administration Of Village Fund: A Case Study In Barru District, Barru Regency. Asian Journal of Social Sciences \& Humanities Vol, 8, 1.

Pasolong, H. (2011). Teori Administrasi Publik. Cetakan ketiga. Bandung: CV. Alfabeta.

Podungge, R. (2010). Peran Pemerintah Daerah dalam Peningkatan Kualitas Pelayanan Bidang Kesehatan. Jurnal Inovasi, 7(01).

Rosdiana, R., Widyastuti, Y., \& Listyaningsih, L. (2017). Kualitas Pelayanan Kesehatan Di Pusat Kesehatan Masyarakat (Puskesmas) Kota Serang. Universitas Sultan Ageng Tirtayasa.

Suprapto. (2019). Implementasi Kebijakan Diskresi pada Pelayanan Kesehatan Badan Penyelenggara Jaminan Kesehatan (Bpjs). Jurnal Ilmiah Kesehatan Sandi Husada, $7(1), 1-8$.

suprapto, N. (2018). Hubungan Komitmen Dan Kepuasan Perawat Dengan Prestasi Kerja Perawat Pelaksana Rumah Sakit DiMakassar. Jurnal Ilmiah Kesehatan Sandi Husada, $8(2$ SE-Articles $)$. Retrieved from https://akper-sandikarsa.ejournal.id/JIKSH/article/view/59

Suprapto, S. (2016). Faktor Stres Kerja Perawat Yang Berhubungan Dengan Mutu Pelayanan Keperawatan Di Instalasi Rawat Darurat Rs Daerah Salewangan Kabupaten Maros - Jurnal Ilmiah Kesehatan Sandi Husada. https://doi.org/10.35816/jiskh.v4i1.77

Suprapto, S. (2017). Studi Kasus Pada Klien Nn. N Dengan Trauma Capitis Ringan Dirawat Unit Gawat Darurat Rumah Sakit Islam Faisal Makassar. Jurnal Ilmiah Kesehatan Sandi Husada.

Suprapto, S. (2018). Pengetahuan Dan Sikap Masyarakat Dalam Upaya Pencegahan Tuberkulosis Di Wilayah Kerja Puskesmas Batua Kota Makassar. Jurnal Ilmiah Kesehatan Sandi Husada, 7(1 SE-Articles). Retrieved from https://akpersandikarsa.e-journal.id/JIKSH/article/view/10

Yayat, R. (2017). Kualitas Pelayanan Publik Bidang Administrasi Kependudukan Di Kecamatan Gamping. Jurnal Ilmiah Magister Ilmu Administrasi (JIMIA),(2), 56-65. 